\title{
MOTIONS OF NEAR-POLAR K-GIANTS ALONG THE Z-COORDINATE
}

\author{
A.N, BALAKIREV \\ Stemberg Astronomical Institute \\ Moscow University \\ Moscow, U.S.S.R.
}

The motion of G8-K5 III, IV stars near galactic poles $\left(|\mathrm{b}|>60^{\circ}\right)$ was investigated. The main attention was paid to motion in the z-direction. The spectral types, visual magnitudes, colors and radial velocities $\left(v_{r}\right)$ were taken mainly from Schild (1973), Heard (1956), Blanco et al (1968) and Wilson (1953). To reduce the values $v_{r}$ by Heard to those by Wilson, the correction of $-1 \mathrm{~km} / \mathrm{sec}$ was made. The stars with variable $\mathrm{v}_{r}$ and spectroscopic binaries were excluded from the investigation.

The study of motion was made by least-squares solution of the system of conditional equations taken at first (calculation 1 ) in the form

$$
-\mathrm{v}_{\mathrm{r}}=\mathrm{U} \odot \cos 2 \cos \mathrm{b}+\mathrm{V} \odot \sin 2 \cos \mathrm{b}+\mathrm{W} \odot \sin \mathrm{b}
$$

where $U_{\odot}, V_{\odot}$, We are the'solar motion components relative to the investigated stars. In order to ascertain whether the value Wo changes with $\mathrm{z}$-coordinate, we made calculation 2 , having replaced in (1) the value $W_{\odot}$ by value $\left(W_{\odot}+\left(d W_{\odot} / d z\right) z\right)$. The $z$-coordinates were defined as the heights above the galactic plane, assuming the Sun's height $\mathrm{z}_{\odot}=10 \mathrm{pc}$. The distances $\mathrm{r}$ were found mainly as luminosity-distances. The intrinsic colors and absolute magnitudes were taken from Bulon (1963) and the ratio $R=A_{V} / E_{B-V}=3.0$ was adopted. The results of calculations for different groups of stars are presented in the Table, where $\mathrm{n}$ is the number of stars. The components of the solar motion found by Vyssotsky and Janssen (195I) (group F) and those relative to G8-K5 III, IV stars from Woolley et al (1970)(group D) are also Iisted. The stars of these groups, belong to the disk population. Although the values $U_{0}$ and $V_{\odot}$ are determined with uncertainty for the investigated stars, still the difference between those values for the groups $A, B$ and $C$ on the one hand and the groups $D$ and $F$ on the other hand appears to be real. This distinction may be accounted for by the presence of the old disk and halo objects among the investigated stars. 


\begin{tabular}{c|rcrr|rr}
\hline \multirow{2}{*}{$\begin{array}{c}\text { Group } \\
\text { of stars }\end{array}$} & \multicolumn{4}{|c|}{ Calculation 1} & \multicolumn{2}{c}{ Calculation 2 } \\
& $U_{\odot \mathrm{km}} / \mathrm{sec}$ & $V_{\odot} \mathrm{km} / \mathrm{sec}$ & $W_{\odot \mathrm{km}} / \mathrm{sec}$ & $\mathrm{n}$ & $d W_{\odot} / d z \mathrm{~km} / \mathrm{sec} / \mathrm{kpc}$ & $\mathrm{n}$ \\
\hline $\mathrm{A}\left(\mathrm{b}>60^{\circ}\right)$ & $7.8 \pm 7.6$ & $41.4 \pm 10.3$ & $7.0 \pm 1.8$ & 157 & $15 \pm 32$ & 89 \\
$\mathrm{~B}\left(\mathrm{~b}<-60^{\circ}\right)$ & $2.6 \pm 8.4$ & $13.1 \pm 7.4$ & $4.8 \pm 2.3$ & 87 & $30 \pm 50$ & 79 \\
$\mathrm{C}\left(|\mathrm{b}|>60^{\circ}\right)$ & $8.6 \pm 5.7$ & $26.4 \pm 6.3$ & $6.5 \pm 1.5$ & 245 & $7 \pm 15$ & 169 \\
$\mathrm{D}$ & $8.8 \pm 3.6$ & $13.7 \pm 2.7$ & $6.3 \pm 2.2$ & 49 & & \\
F & 10 & 10 & 6.2 & & \\
\hline
\end{tabular}

The quantity $d W_{\odot} / \mathrm{dz}$ is determined with great uncertainty, although it is quite possible that the small positive value of it is real. This should mean that the subsystem of investigated stars is contracting towards the galactic plane, the farther the stars outward from the plane the greater the speed of contraction. But further we shall assume that dWo $/ \mathrm{dz}=0$.

The residual radial velocities $\left(\Delta v_{r}\right)$ contain information on peculiar $W$-velocities of the investigated stars $(\mathrm{w})$. The knowledge of w makes it possible to determine the dynamic parameter $C$ in the form (see Kuzmin, 1952) :

$$
C^{2}=\left(\sigma_{W}^{2} / \sigma_{z}^{2}\right)=-\left(d^{2} \Phi / d^{2} z\right)_{0}
$$

where $\Phi$ is the galactic potential for the unit mass, $\sigma^{2}$ is the dispersion of $\mathrm{z}$ and $\sigma_{\mathrm{W}}^{2}$ is the dispersion of $\mathrm{w}$ of investigated stars. The parameter $\mathrm{C}$ is related to the constants of differential galactic rotation $\mathrm{A}$ and $\mathrm{B}$ by Poisson's law

$$
4 \pi G \rho=C^{2}-2\left(A^{2}-B^{2}\right)
$$

where $G$ is the gravitational constant and $\rho$ is the total mass density near the Sun.

To find $\mathrm{C}$ we shall use the values $\Delta \mathrm{v}_{\boldsymbol{r}}$ instead of true values $\mathrm{w}$. Such substitution results in the increase of the value $\sigma_{\mathrm{W}}^{2}$ relative to reality and therefore, according to (2), in the increase of the value $C$. But the nearer the star is to the pole, the more accurate is the assumption that $\Delta \mathrm{v}_{\mathrm{r}}$ is equal to $\mathrm{w}$. Using the stars with $|\mathrm{b}|>750$ (group 1,60 stars) and with $|\mathrm{b}|>840$ (group 2,18 stars) we found $\mathrm{C}$ equal to $157 \pm 14 \mathrm{~km} / \mathrm{sec} / \mathrm{kpc}$ and to $103 \pm 17 \mathrm{~km} / \mathrm{sec} / \mathrm{kpc}$, respectively. Having substituted $A=15 \mathrm{~km} / \mathrm{sec} / \mathrm{kpc}, B=-10 \mathrm{~km} / \mathrm{sec} / \mathrm{kpc}$ and $\mathrm{C}$ $=103 \pm 17 \mathrm{~km} / \mathrm{sec} / \mathrm{kpc}$ in (3) we found $\rho=0.15 \mathrm{M \odot} / \mathrm{pc}^{3}$. Such total mass density does not correspond to the observed mass density near the Sun, $\rho_{\mathrm{obs}} \approx 0.09 \mathrm{Mo} / \mathrm{pc}^{3}$, universally recognized at present. The investigated stars appear to be a mixture of disk population, old disk population and halo objects. But the formula (2) is strictly correct only near the galactic plane, where the condition 


$$
d^{2} \Phi / d^{2} z=\text { const }=-C^{2}
$$

is satisfied. Therefore only the disk population stars may be used for such study. Besides, such mixture results in the increase of velocity dispersion and in the increase of value $C$. But there is no method for classification of each star under investigation according to population type.

We try to do this with the help of modulus w - modulus $z$ $(|w|-|z|)$ graph (Fig.1). In the region where the condition (4) holds, the stars move along the z-coordinate according to the law (see Parenago, (1954)

$$
\ddot{z}=\left(d^{2} \Phi / d^{2} z\right) z=-C^{2} z
$$

where $\ddot{z}$ isthe acceleration. Then the trajectory of the star's motion in the coordinate plane $w-z$ is an ellipse with semiaxes $z^{0}$ and $\mathrm{W}^{0}=\mathrm{C} \mathrm{Z0}$, where $\mathrm{Z}_{0}$ is the amplitude in the $\mathrm{z}$-direction and $\mathrm{W}^{0}$ is the amplitude of the w-velocity. Suppose that the quantity $\mathrm{C}$ is close to that found by oort (1932) ( $0=73 \mathrm{~km} / \mathrm{sec} / \mathrm{kpc})$, which corresponds to the total mass density $\rho=\rho_{\mathrm{obs}}=0.09 \mathrm{M} \odot / \mathrm{pc}^{3}$ exactly. This condition leads to some trajectories in the plane $w-z$ (see Fig.I). The curve 1 is such a trajectory with amplitude $Z_{0}=500 \mathrm{pc}$ and the curve 2 is that with amplitude $\mathrm{ZO}=360 \mathrm{pc}$. If the investigated stars move according to the law (5) (i.e. are the disk population stars) the stars below the curves may not have $\mathrm{z}$-coordinates higher than the corresponding $\mathrm{Z} 0$.

$|w| \mathrm{km} / \mathrm{sec}$

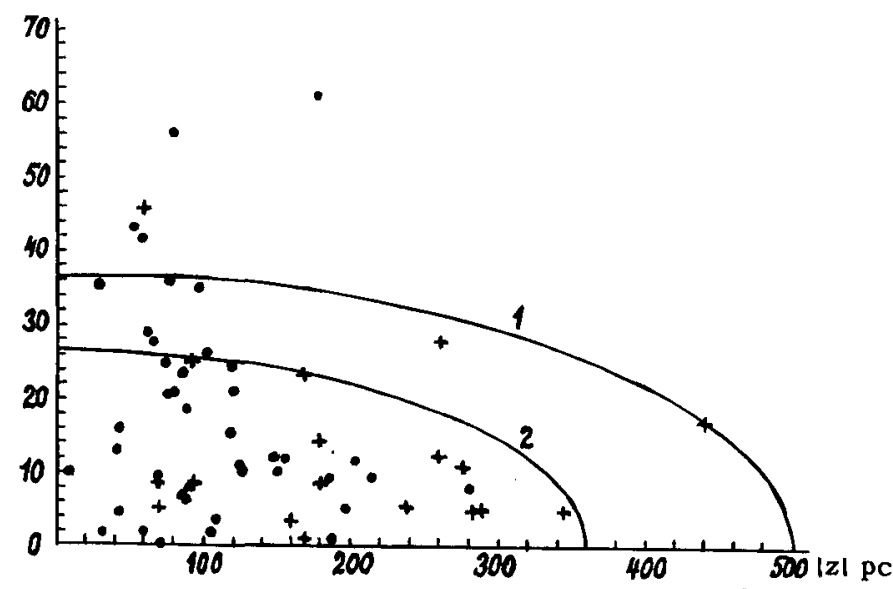

Figure 1. The $|w|-|z|$ graph for stars with $|b|>75^{\circ}$; crosses are the stars with $|b|>84^{8}$. points ore oll the other stars. 
Using the stars of group 2 below the curve 1 we obtain $C=79 \pm 13 \mathrm{~km} /$ $\mathrm{sec} / \mathrm{kpc}$ and using those stars below the curve 2 we obtain $\mathrm{C}=76 \pm 14$ $\mathrm{km} / \mathrm{sec} / \mathrm{kpc}$. Hence the flatter the stars we study, the nearer to $\mathrm{Co}$ is the quantity of the dynamic parameter. The value $\mathrm{C}=76 \pm 14 \mathrm{~km} / \mathrm{sec} /$ $\mathrm{kpc}$ corresponds to $\rho=0.11 \pm 0.02 \mathrm{M} \odot / \mathrm{pc}^{3}$. That is in good agree-

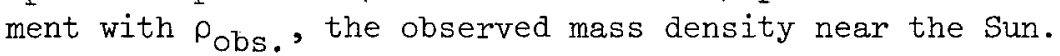

\section{References}

BLANCO, V.M., DEMERS, S., DOUGLASS, G.G., FITZGERALD, M.P.:

1968, Publ. U.S. Naval Obs., second ser., XX, Washington. BULON, J.:

1963, Publ. Obs. Haute-Provence, 6, 187.

HEARD, J.F. :

1956, Publ. David Dunlap Obs., $2,107$.

KUZMIN, G.G.:

1952, Publ. Tartu Astron. Obs. 32,5.

OORT, J.H.:

1932, Buבl. Astron.Inst.Neth. 6, 249.

PARENAGO, P.P.:

1954, Kurs zvezdnoj astronomii, Gostechizdat, Moscow, p. 402.

SCHILD, R.E.:

1973, Astron.J., 78, 37.

VYSSOTSKY, A.N., JANSSEN, E.A.:

1951, Astron.J., 56.58.

WILSON, R.E.:

1953, General Catalogue of Stellar Radial Velocities, Carnegie Inst.

of Washington, Washington, D.C.

WOOLLEY, R., EPPS, E.A., PENSTON, M.J., POCOCK, S.B.:

1970, Roy. Obs. Ann., No.5.

The full text of this paper is published in Astron.zhur.

SSSR 1976, 53, 1 (see Soviet Astronomy 1976, 20, 64). 